Somego, M. (1976): Chromosome number of in four Alnus species of sect. Bifurcates. Bulletin of the Government Forest Experiment Station Meguro. 287: 77-84.

StarodubtSeV, V. N. (1997): Chromosome numbers in some rare species of vascular plants from the Russian Far East. Botaničeskij Žurnal (Moscow \& Leningrad): 121-122.

Stebbins, G. L. (1971): Chromosomal evolution in higher plants. London: Edward Aronld LTD, 87-93.

Watanabe, K., R. M. King, T. YahaRA, M. Ito, J. YoKoYAMA, T. SUZUKI and D. J. CRAWFord (1995): Chromosomal cytology and evolution in Eupatorieae (Asteraceae). Ann Mis Botany Garden 82: 581-592.
Watanabe, K., T. Yahara, T. Denda and K. Kosuge (1999): Chromosomal evolution in the genus Brachyscome (Asteraceae, Astereae): statistical tests regarding correlation between changes in karyotype and habit using phylogenetic information. Journal Plant Research 112: $145-161$.

ZARCO, C. R. (1986): A new method for estimating karyotype asymmetry. Taxon 35: 526-530.

\title{
Realized Genetic Gains in Coastal Douglas-fir in British Columbia: Implications for Growth and Yield Projections
}

\author{
By M. StoenR ${ }^{1), 4)}$, K. BirD ${ }^{2)}$, G. Nigh ${ }^{1)}$, J. Woods ${ }^{3)}$ and A. YAnchuK ${ }^{1)}$
}

(Received 10 ${ }^{\text {th }}$ November 2009)

\begin{abstract}
Realized genetic gain trials for coastal Douglas-fir (Pseudotsuga menziesii (Mirb.) Franco) at five different sites with four different spacings were assessed at age 12 to compare early gain predictions in growth from small plot progeny test designs to those obtained from large block designs. Seedlings from three genetic levels, i.e., local wild-stand controls (WS), a mid-gain seedlot (MG), and a top-cross seedlot (TC) were planted in $12 \mathrm{x}$ 12 tree plots with two replications at spacings of $1.6 \mathrm{~m}$, $2.3 \mathrm{~m}, 2.9 \mathrm{~m}$ and $4.0 \mathrm{~m}$. Two replications of a "single-tree plot" design at $2.9 \mathrm{~m}$ spacing for the three genetic levels (30 trees per genetic level) were also established, to allow for more detailed comparisons between single-tree

1) Research Branch, British Columbia Ministry of Forests and Range, 727 Fisgard St,.Victoria, BC, V8W 1R8, Canada.

2) Research Branch, British Columbia Ministry of Forests and Range, Cowichan Lake Research Station, 7060 Forestry Road, Mesachie Lake, BC, V0R 2N0, Canada.

$\left.{ }^{3}\right)$ Forest Genetics Council of BC, 3370 Drinkwater Road, Duncan, BC, V9L 5Z2, Canada.

4) Communicating author: Michael Stoenr. Telephone 250-3566269, Fax 250-387-0046. E-Mail: michael.stoehr@gov.bc.ca
\end{abstract}

and multiple-tree plot means. Although these trials are still relatively young, trees in the closest spacing had the highest levels of mortality with the TC trees having the highest rate of survival. Height gains in the block trials ranged from $10.4 \%$ to $16.1 \%$ for MG and TC trees, respectively, and were relatively close to the predicted values; however, volume (individual tree and volume/ha) gains exceeded expectations. Effects of genetic entry on height at age 12 were highly significant, while spacing, genetic entry by spacing, and genetic entry by test site interactions were not significant. We also compared height growth over the first 12 years to growth estimated from the "Bruce height growth model" for Douglas-fir and found that on four of the five test sites our MG and TC seedlings follow the expected height growth trajectories.

Key words: Pseudotsuga menziesii, breeding value, competition, spacing.

\section{Introduction}

The genetic improvement program for coastal Douglas-fir (Pseudotsuga menziesii (Mirb.) Franco) in 
British Columbia (BC) started in the late 1950s with the pioneering work of Alan Orr-Ewing (1969). The program has now advanced to the level where second generation seed orchards are established and testing and selection have begun for third generation orchards (STOEHR et al., 2008).

Parent tree breeding values for commercial traits are typically estimated using progeny tests either established with single-tree or small multiple-tree (4-9) row plots. However, the single-tree plot designs can exaggerate family differences due to competition effects among trees of different sizes following crown closure (MAGNUSSEN, 1989), while in row-plots, members of the same family have a higher probability of sampling the same microenvironment (MAGNUSSEN, 1993), thus reducing estimates of environmental variation. Both may lead to overestimation of heritabilities and gain in growth traits. In order to assess how the offspring of selected parent genotypes perform in a mixture with other genotypes selected for growth, and to see if predicted growth gains are observed through to rotation, realized genetic gains tests have been established for many species around the world (DHAKAL et al., 1996; CARSON et al., 1999 a,b; LAMBETH, 2000; Vergara et al., 2007; St. ClaIR et al., 2004; WENG et al., 2008).

Genetic gains in BC are typically estimated from progeny test height and diameter measurements at several ages, usually ranging from 5 to $15 \mathrm{yrs}$, and are then extrapolated to merchantable volume at some rotation age (60 to 80 years, depending on the species). This extrapolation includes an adjustment factor for age-age (juvenile-mature) correlations (LAMBETH, 1980), which accounts for an imperfect correlation between measurement (selection) age (e.g., 12 or 15 yrs) and rotation age. In addition, a factor of 2 is currently used to approximate volume breeding values (BVs) from height BVs when only height data are available (XIE and YANCHUK, 2003). For coastal Douglas-fir in BC, the BRUCE (1981) height growth model is used in the Table Interpolation Program for Stand Yields (TIPSY) stand yield simulator (Mitchell et al., 2004) to predict stand volumes for coastal Douglas-fir. The average BVs of the parents used in the seedlot to establish a stand are considered in TIPSY through an adjustment to the underlying site index assigned to the stand. This increased site index is modeled through to a stand harvest age using the Bruce model.

Realized genetic gain trials will be more commonly used to adjust and modify growth and yield models to predict merchantable volume at harvest of forest stands established with seedlings from parents selected for improved growth. A common caveat is that growth and yield models are based on non-selected seedling stock, yet these models have the advantage of being based on large sample sizes with juvenile and mature trees growing across a wide range of sites (CARSON et al., 1999b). Questions arise when standard growth models use data from selected seedlings, which are based on a much smaller sample size and a limited number of sites, to predict future volume production in operational plantations. In an earlier study, no differences were found in yield equations between selected and non-selected stands in loblolly pine (Pinus taeda L.) as long as the average height of dominant and codominant trees and the number of surviving trees were specified correctly by correspondingly increasing the site index (SI) (BUFORD and BURKHART, 1987). However, increasing SI alone may not account for the total increase in volume production if the corresponding diameter increases observed in selected seedlings are not incorporated into the determination of the volume. Interestingly, the observed shapes of the growth and yield curves in loblolly pine did not change due to the level of genetic selection of the planted seedlings (BUFORD and BURKHART, 1987). ADAMS et al. (2006) further improved volume predicitons for loblolly pine by developing family-specific site indices.

The use of genetic multipliers has been suggested as a method to improve predicted yields given increased growth rates in height as well as diameter (GouLD et al., 2008; CARSON et al., 1999b). For example, in the CARSON et al. (1999b) study, selected seedlings had height increases of $5.1 \%$, while basal area increased by $13 \%$. This dual improvement could not be adeqautely captured by a lift in SI alone, and hence required the application of a genetic multiplier.

Here we evaluate the differences in predicted genetic gains and the realized gains in mid-gain and high-gain seedlots observed in large block plots established across a range of stand densities that bracket normal operational plantation spacing. The higher density treatments impart substantial inter-stem competition at an early age. This trial, therefore, examines if seedlings from selected parent trees grow as anticipated when subjected to strong intra-specific competition from cohorts of similar genetic quality, as in plantations established with seed orchard seed. Although the data are obtained from trees that are still relatively young, a secondary objective is to determine if the growth trajectories among levels of genetically selected stock follow that currently predicted from current site index projection approaches used for coastal Douglas-fir.

\section{Materials and Methods}

\section{Seedling Production}

Three distinct levels of genetic quality, namely wild stand (wind-pollinated) control (WS), mid-gain (MG) and a top-cross (TC) trees, were produced by control-crossing of parents of known genetic quality as per their predicted parental BVs. Parental BVs, based on gross volume (OMULE et al., 1987, see below for details) were estimated using 12-year height and diameter at breast height (dbh) data from multiple sets of a 6-tree non-overlapping half-diallel mating design, with offspring from each parent planted on 11 field tests distributed throughout the maritime seed zone of south western British Columbia (Woods, 1993). BVs were predicted using best linear predictions (BLP), expressed as percentage gains at age 60 years for volume over the non-selected population mean (White and Hodge, 1989). These BVs included an age-age correlation to account for uncertainty between selection age (12 yrs) and harvesting age (60 yrs) of 0.5 (LAMBETH, 1980). 
Seedlings used to represent the wild-stand control were grown from a mix of six seedlots collected from local commercial natural stand collections. Seedlings of the mid-gain (MG) group were single-pair control pollinations between parent trees with BVs ranging between -2 and 20 . The BVs of the resulting 17 full-sib families ranged from 9 to 12 with an MG BV average of 10 (i.e., $10 \%$ volume gain at rotation). The TC entries were also single-pair control crosses among 10 parents with individual parental BVs ranging from 17 to $26 \%$, with an average BV of $18 \%$ based on 22 families. Each parent in the control crosses (MG and TC entries) were used in more than one family, except parent \#243, which was only used as a pollen donor for one family. All parents in the WS seedlots originated from the coastal Douglas-fir low elevation seed planning zone $(<700 \mathrm{~m})$. While the number of seedlings per full-sib family planted per site varied among families (ranging from 10 to 195 for MG and TC), the number of seedlings of the six WS seedlots was relatively constant across site (i.e., about 200 seedlings). Seeds were sown after four weeks of stratification at the Cowichan Lake Research Station, located on southern Vancouver Island, in 415B styro-blocks (108 $\mathrm{ml}$ root plug volume) filled with a standard peat-vermiculite-perlite mix (60:20:20 ratio by volume) in late March 1995. Growing conditions in the greenhouse followed standard protocols. Seedlings were lifted in early winter and stored in a freezer at $-2{ }^{\circ} \mathrm{C}$ until planting in the spring of 1996.

\section{Test Establishment and Maintenance}

Tests were established on six sites representing a range of site quality (SI) typical of the coastal Douglasfir maritime zone. One site was destroyed by a wild fire, leaving five test sites for analysis (Table 1a). The test design was a randomized block split-plot, with the the main plot factor 'Spacing' having four levels $(1.6 \mathrm{~m} \mathrm{x}$ $1.6 \mathrm{~m}, 2.3 \mathrm{~m} \times 2.3 \mathrm{~m}, 2.9 \mathrm{~m} \times 2.9 \mathrm{~m}, 4.0 \mathrm{~m} \times 4.0 \mathrm{~m})$ arranged in two randomized blocks. The split plot factor was 'Genetic Group', having three levels (WS, MG, TC) arranged in plots of $12 \times 12$ seedlings per combination of block, spacing level and genetic group. In total, each site contains 2 blocks x 4 spacing levels x 3 genetic classes $\mathrm{x}$ 144 trees $=3456$ trees. The family identity of each test tree in the MG and TC group was maintained (i.e., both male and female parent known). When spacing changed between main plots, two rows of surround trees (one row each at the neighbouring spacing) were planted to reduce spacing effects on plot boundaries. However, all plot perimeter trees were removed from the analysis, leaving $100(10 \times 10)$ trees for evaluation in each spacing $\mathrm{x}$ genetic entry treatment combination (plot).

In addition to this layout, an additional area in each block was set up with single-tree plots (STP) to compare results between the two designs over time. In the STP, 30 seedlings, randomly chosen from each genetic class, were planted at a spacing of $2.9 \mathrm{~m}$.

All test sites were regularly brushed to keep the nontest tree competition at a minimum. Heights of each seedling were measured in the fall of 1997, 1998, 2001 and 2006. Root collar diameter and dbh were measured in 2001 and in 2006, respectively.

\section{Analyses}

We conducted two types of analyses for this study. First, we carried out separate analyses to evaluate the performance of the MG and TC seedlings in comparison to WS controls in multiple-tree plots and single-tree plots. Secondly, we compared the observed height growth of each genetic entry across test sites to the BRUCE (1981) height growth model to determine if the height growth trajectories are similar to those expected under the growth and yield systems applied in BC.

Actual (observed) realized genetic gain (RGG) was calculated as:

$$
\begin{aligned}
\mathrm{RGG}= & 100 \cdot\left(\overline{\mathrm{X}}_{\mathrm{MG} \mathrm{or} \mathrm{TC}}-\overline{\mathrm{X}}_{\mathrm{WS}}\right) / \overline{\mathrm{X}}_{\mathrm{WS}}, \\
& \text { where } \overline{\mathrm{X}}_{\mathrm{WS}}, \mathrm{MG} \text { or TC } \\
& \text { are the respective genetic entry means. }
\end{aligned}
$$

Height and dbh data in 2006 (ht06, d06) were used to calculate individual total tree volume as:

$$
\begin{aligned}
\ln \left(\text { vol06 in } \mathrm{m}^{3}\right)= & -9.896325907+1.83478844 . \\
& \ln (\mathrm{d} 06 \text { in } \mathrm{cm})+1.00511916 . \\
& \ln (\text { ht06 in } \mathrm{m})(\text { OMULE et al., } 1987) .
\end{aligned}
$$

Plot means of ht06, d06, and vol06 were subjected to ANOVA (via REML estimation) using the MIXED procedure in SAS (SAS InsTITUTE INC., 2004) according to the following linear model:

$$
\begin{aligned}
\mathrm{Y}_{\mathrm{ijklm}}= & \mu+\mathrm{L}_{\mathrm{i}}+\mathrm{B}_{\mathrm{j}(\mathrm{i})}+\mathrm{S}_{\mathrm{k}}+\mathrm{LS}_{\mathrm{ik}}+\mathrm{BS}_{\mathrm{j}(\mathrm{i}) \mathrm{k}}+\mathrm{G}_{\mathrm{l}} \\
& +\mathrm{LG}_{\mathrm{il}}+\mathrm{BG}_{\mathrm{j}(\mathrm{i}) \mathrm{l}}+\mathrm{SG}_{\mathrm{kl}}+\mathrm{LSG}_{\mathrm{ikl}}+\mathrm{BSG}_{\mathrm{j}(\mathrm{i}) \mathrm{kl}}
\end{aligned}
$$

where: $\mathrm{Y}_{\mathrm{ijkl}}$ the plot means of ht06 or d06 or vol06

$\mu=$ the overall mean

$\mathrm{L}_{\mathrm{i}}=$ the random effect of test site location, with $\mathrm{i}=1 . . .5$

$\mathrm{B}_{\mathrm{j}(\mathrm{i})}=$ the random effect of block nested within site, with $\mathrm{j}=1,2$.

$\mathrm{S}_{\mathrm{k}}=$ the fixed effect of spacing; $\mathrm{k}=1,2,3,4$ (main-plot factor).

$\mathrm{G}_{1}=$ the fixed effect of the genetic class; $1=1,2,3$ (splitplot factor).

The remaining terms are interaction terms of the main effects. $\mathrm{BSG}_{\mathrm{j}(\mathrm{i}) \mathrm{kl}}$ was considered the residual error (experimental error). Fixed effects were tested by the default F-test denominator given by SAS Proc Mixed. Random effects were not tested for significance, but expressed as variance components only.

To evaluate fixed effects of full-sib families on performance across the five sites and the four levels of spacing, BLUEs (best linear unbiased estimates) were generated using SAS Proc Mixed. The following linear family model was fit:

$$
\mathrm{Y}_{\mathrm{ijkl}}=\mu+\mathrm{L}_{\mathrm{i}}+\mathrm{B}_{\mathrm{j}(\mathrm{i})}+\mathrm{I}_{\mathrm{k}}+\mathrm{LI}_{\mathrm{ik}}+\mathrm{BI}_{\mathrm{j}(\mathrm{i}) \mathrm{k}}+\operatorname{residual}_{(\mathrm{ijk}) \mathrm{l}}
$$

where $\mathrm{Y}_{\mathrm{ijkl}}=$ volume $\left(\mathrm{dm}^{3}\right)$ of the $\mathrm{l}^{\text {th }}$ seedling in block $\mathrm{j}$ of location in family $\mathrm{k}$;

and $\mu, L$ and $B$ are defined as above and $I_{k}$ is the fixed effect of individual full-sib families.

The graphical comparison between the observed and predicted height growth (from Bruce's (1981) height growth model) was done by first selecting the 'site trees' from each plot in the study at ages 3, 4, 7, and 12 (the ages at which height measurements were taken). Site 


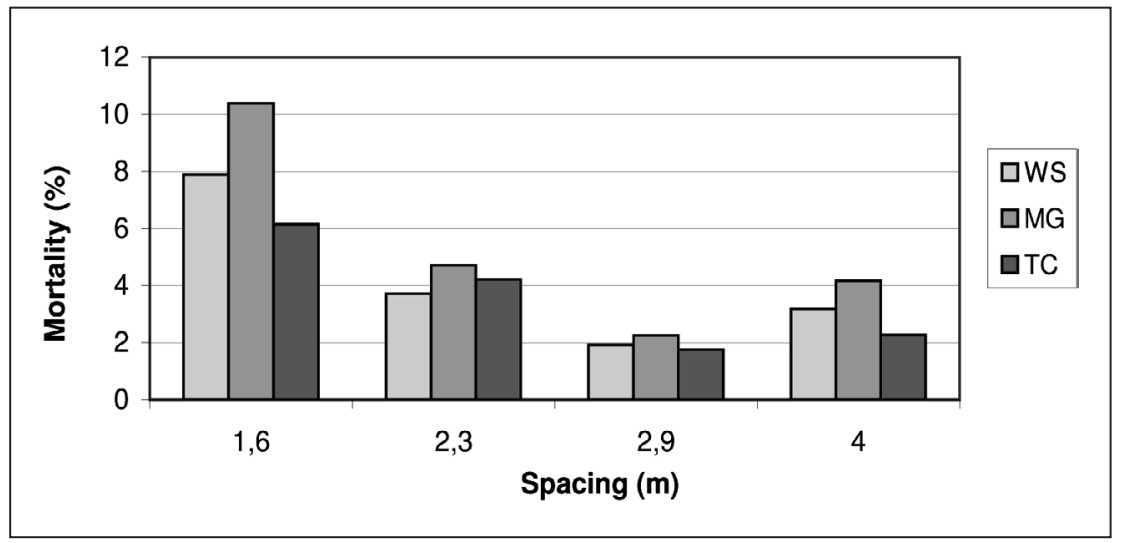

Figure 1. - Mortality between age 4 and age 12 in genetic gain trials on five sites by three level of genetic groups in coastal Douglas-fir.

trees are the equivalent of the largest 100 tallest trees per hectare. The average height of the site trees in the plot is the top height for the plot. The top heights were averaged by site, genetic level, and age and the top height trajectories were plotted by site and genetic level, along with the predicted top height from Bruce's (1981) height growth model for site indexes 40,45 , and $50 \mathrm{~m}$ at breast height age 50 .

\section{Results}

Mortality due to competition was assessed as the differences in survival between ages 4 and 12. This eliminated mortality that was likely due to early establishment problems, and showed the anticipated effects of the narrow spacing and increased competition at age 12 . As expected, age 12 mortality was highest in the $1.6 \mathrm{~m}$ spacing (statistical significance was not tested). Survival

Table 1a. - Block means (standard deviations) for height and diameter of coastal Douglas-fir growing on five sites and planted at four spacings using wild stand (WS), mid-gain (MG) and top-cross (TC) trees in a realized gain trial measured at age 12.

\begin{tabular}{|c|c|c|c|c|c|c|c|}
\hline \multirow[t]{2}{*}{ Site } & \multirow[t]{2}{*}{ Spacing } & \multicolumn{3}{|c|}{ Height (m) } & \multicolumn{3}{|c|}{ Diameter $(\mathrm{cm})$} \\
\hline & & WS & MG & $\mathrm{TC}$ & WS & MG & $\mathrm{TC}$ \\
\hline Campbell River & 1.6 & $5.78(1.0)$ & $5.99(0.8)$ & $8.07(1.3)$ & $6.5(1.3)$ & $7.1(1.2)$ & $8.8(1.7)$ \\
\hline lat: $50^{\circ} 0^{\prime} 11^{\prime \prime} \mathrm{N}$ & 2.3 & $6.00(1.0)$ & $7.05(1.1)$ & $6.78(1.1)$ & $7.7(1.7)$ & $9.1(1.7)$ & $8.5(1.6)$ \\
\hline long: $125^{\circ} 17^{\prime} 13^{\prime \prime} \mathrm{W}$ & 2.9 & $5.42(1.4)$ & $6.18(1.9)$ & $5.92(1.3)$ & $7.1(2.0)$ & $8.5(2.6)$ & $7.8(1.9)$ \\
\hline elev: $100 \mathrm{~m}$ & 4.0 & $6.51(1.2)$ & $7.40(1.0)$ & $7.81(1.2)$ & $9.4(2.2)$ & $11.1(2.0)$ & $11.9(2.5)$ \\
\hline Lang Bay & 1.6 & $4.96(1.2)$ & $5.64(1.3)$ & $6.29(1.3)$ & $5.2(1.4)$ & $5.5(1.3)$ & $6.4(1.6)$ \\
\hline lat: $49^{\circ} 48^{\prime} 24^{\prime \prime} \mathrm{N}$ & 2.3 & $4.66(1.1)$ & $5.53(1.0)$ & $5.51(0.9)$ & $5.1(1.5)$ & $6.0(1.3)$ & $5.9(1.2)$ \\
\hline long: $124^{\circ} 22^{\prime} 22^{\prime \prime} \mathrm{W}$ & 2.9 & $5.20(1.0)$ & $5.48(0.9)$ & $5.69(0.9)$ & $5.8(1.3)$ & $6.2(1.2)$ & $6.5(1.3)$ \\
\hline elev: $135 \mathrm{~m}$ & 4.0 & $4.92(1.0)$ & $5.20(1.0)$ & $5.79(1.2)$ & $5.9(1.5)$ & $6.4(1.4)$ & $7.1(1.7)$ \\
\hline Norrish & 1.6 & $7.45(1.0)$ & $8.23(1.0)$ & $8.37(0.9)$ & $8.2(1.4)$ & $9.0(1.4)$ & $9.3(1.3)$ \\
\hline lat: $49^{\circ} 13^{\prime} 48^{\prime \prime} N$ & 2.3 & $7.55(1.1)$ & $7.94(0.9)$ & $8.38(1.0)$ & $9.1(1.5)$ & $9.5(1.3)$ & $10.0(1.4)$ \\
\hline long: $122^{\circ} 9^{\prime} 38^{\prime \prime} \mathrm{W}$ & 2.9 & $6.99(1.0)$ & $7.91(1.0)$ & $8.74(0.9)$ & $9.0(1.6)$ & $9.9(1.5)$ & $11.7(1.5)$ \\
\hline elev: $550 \mathrm{~m}$ & 4.0 & $7.59(1.2)$ & $7.73(1.2)$ & $8.39(1.2)$ & $10.8(2.2)$ & $11.2(2.2)$ & $12.2(2.5)$ \\
\hline Robertson & 1.6 & $6.07(1.1)$ & $7.20(1.2)$ & $7.34(0.8)$ & $7.0(1.5)$ & $8.0(1.6)$ & $8.1(1.2)$ \\
\hline lat: $48^{\circ} 45^{\prime} 55^{\prime \prime} \mathrm{N}$ & 2.3 & $5.81(1.0)$ & $6.73(0.9)$ & $6.56(1.0)$ & $7.2(1.5)$ & $8.7(1.4)$ & $8.3(1.5)$ \\
\hline long: $124^{\circ} 7^{\prime} 16^{\prime \prime} \mathrm{W}$ & 2.9 & $5.98(1.1)$ & $6.64(1.2)$ & $6.37(1.0)$ & $7.7(1.7)$ & $8.7(1.6)$ & $8.3(1.6)$ \\
\hline elev: $220 \mathrm{~m}$ & 4.0 & $6.62(1.2)$ & $6.86(1.1)$ & $7.00(1.2)$ & $9.6(2.3)$ & $9.6(1.7)$ & $9.9(2.3)$ \\
\hline Spirit Lake & 1,6 & $5.26(1.0)$ & $5.78(1.1)$ & $5.87(0.9)$ & $5.9(1.3)$ & $6.4(1.4)$ & $6.4(1.2)$ \\
\hline lat: $50^{\circ} 14^{\prime} 49^{\prime \prime} \mathrm{N}$ & 2,3 & $3.78(1.1)$ & $4.40(1.1)$ & $5.02(1.0)$ & $4.6(1.6)$ & $5.5(1.6)$ & $6.3(1.4)$ \\
\hline long: $125^{\circ} 41^{\prime} 11^{\prime \prime} \mathrm{W}$ & 2,9 & $4.79(1.0)$ & $5.20(1.0)$ & $5.55(1.0)$ & $6.2(1.4)$ & $6.7(1.3)$ & $7.1(1.4)$ \\
\hline elev: $232 \mathrm{~m}$ & 4,0 & $4.46(1.1)$ & $4.87(1.2)$ & $5.04(1.2)$ & $6.0(1.7)$ & $6.4(1.6)$ & $6.7(1.8)$ \\
\hline
\end{tabular}


Table 1b. - Block means (standard deviations) for individual tree total volume and expressed as volume per hectare for coastal Douglas-fir growing on five sites and planted at four spacings using wild stand (WS), mid-gain (MG) and top-cross (TC) trees in a realized gain trial measured at age 12.

\begin{tabular}{|c|c|c|c|c|c|c|}
\hline \multirow[t]{2}{*}{ Site } & \multirow[t]{2}{*}{ Spacing } & \multicolumn{2}{|c|}{ Vol/tree $\left(\mathrm{dm}^{3}\right)$} & \multicolumn{3}{|c|}{ Vol/ha $\left(\mathrm{m}^{3)}\right.$} \\
\hline & & WS & MG & WS & MG & TC \\
\hline \multirow[t]{4}{*}{ Campbell River } & 1.6 & $9.9(4.7)$ & $11.7(4.6) 24.1(10.5)$ & 35.9 & 41.0 & 87.9 \\
\hline & 2.3 & $14.2(7.0)$ & $22.1(5.7) 19.0(9.2)$ & 24.2 & 35.0 & 32.0 \\
\hline & 2.9 & $11.8(7.8) 1$ & $19.5(14.3) 14.7(8.5)$ & 13.4 & 22.5 & 16.9 \\
\hline & 4.0 & $22.3(11.0)$ & $33(14.4) 70.5(19.2)$ & 12.8 & 18.8 & 24.6 \\
\hline \multirow[t]{4}{*}{ Lang Bay } & 1.6 & $6.0(3.6)$ & $7.4(4.7) 10.9(6.4)$ & 23.4 & 29.0 & 41.2 \\
\hline & 2.3 & $5.6(3.6)$ & $8.2(4.2) \quad 7.9(3.7)$ & 10.4 & 15.2 & 14.9 \\
\hline & 2.9 & $7.5(3.9)$ & $8.7(4.4) \quad 9.7(4.9)$ & 8.9 & 10.0 & 11.2 \\
\hline & 4.0 & $7.3(4.2)$ & $8.7(4.7) 12.1(7.6)$ & 4.5 & 5.2 & 7.5 \\
\hline \multirow[t]{4}{*}{ Norrish } & 1.6 & $19.0(7.0)$ & $24.7(8.6) 26.3(7.7)$ & 56.9 & 63.7 & 76.1 \\
\hline & 2.3 & $23.5(8.7)$ & $26.3(8.7) 30.5(10.3)$ & 44.0 & 49.1 & 55.9 \\
\hline & 2.9 & $21.5(9.2)$ & $8.2(10.0) 72.1(12.4)$ & 24.4 & 32.3 & 49.4 \\
\hline & 4.0 & $32.5(12.8) 3$ & $35.5(15.4) 45.4(20.4)$ & 20.0 & 21.0 & 25.8 \\
\hline \multirow[t]{4}{*}{ Robertson } & 1.6 & $12.0(6.1)$ & $18.1(8.4) 18.1(6.4)$ & 43.1 & 64.8 & 68.9 \\
\hline & 2.3 & $12.1(5.7)$ & $19.1(7.3) 17.4(7.6)$ & 22.8 & 34.8 & 30.5 \\
\hline & 2.9 & $14.2(8.0)$ & $19.3(9.0) 16.9(7.9)$ & 16.0 & 22.3 & 19.6 \\
\hline & 4.0 & $23.6(13.2)$ & $23.7(9.9) 26.5(14.6)$ & 14.1 & 13.9 & 15.3 \\
\hline \multirow[t]{4}{*}{ Spirit Lake } & 1.6 & $7.7(3.8)$ & $9.8(5.1) \quad 9.8(4.5)$ & 29.6 & 37.6 & 37.5 \\
\hline & 2.3 & $4.0(3.2)$ & $6.0(4.3) \quad 8.2(4.7)$ & 6.8 & 10.2 & 14.0 \\
\hline & 2.9 & $7.8(4.5)$ & $9.5(4.7) 11.2(5.8)$ & 9.3 & 11.0 & 13.2 \\
\hline & 4.0 & $7.2(5.3)$ & $8.7(5.8) \quad 9.8(7.4)$ & 4.3 & 5.1 & 5.9 \\
\hline
\end{tabular}

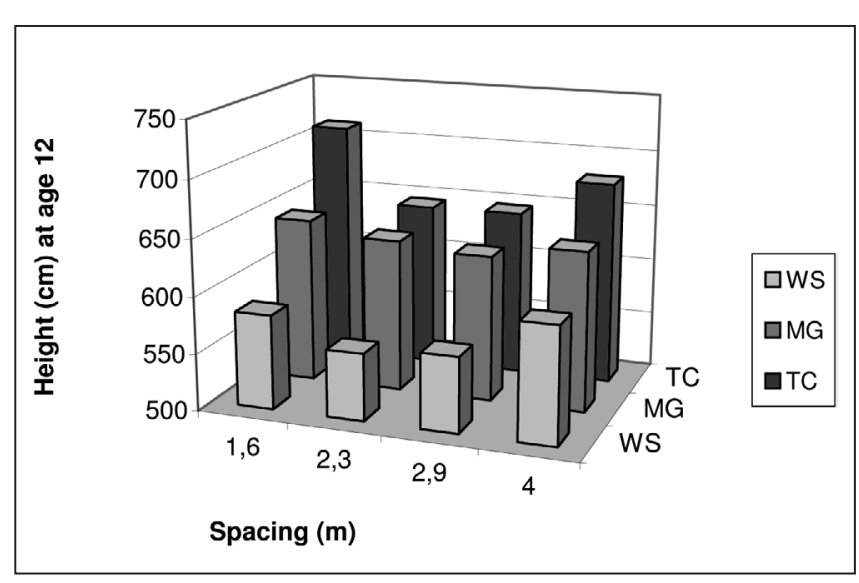

Figure 2. - Age 12 heights in coastal Douglas-fir realized gain trial by spacing and genetic group. was generally highest in the TC blocks and lowest in MG blocks (Figure 1).

Means of measured heights and dbh are listed in Table 1a, and in Table $1 b$ for individual total tree volume and volume per ha for each genetic class, spacing and test location. The TC trees performed better than the MG trees, which were all taller than the WS trees (Fig. 2). Surprisingly, the tallest trees were not always in the narrowest spacing, but dbh was generally greatest in the widest spacing (Table 1a). Volume per tree was extrapolated, accounting for mortality in the test plots, to volume per ha. In all cases, volume per ha was highest in the $1.6 \mathrm{~m}$ spacing, primarily due to the number of trees per ha given this close spacing and good height growth. In general, for the other spacings, vol per ha was driven by the planting density (Table $1 b$ ).

Table 2. - Observed means (SE) for height, diameter, individual tree grossl volume and projected volume per hectare and their percentage gain at age 12 in a coastal Douglas-fir realized gain trial across five sites and four spacings.

\begin{tabular}{|c|c|c|c|c|c|c|c|c|}
\hline & Height (m) & $\%$ & Diameter $(\mathrm{cm})$ & $\%$ & Volume $\left(\mathrm{dm}^{3}\right)$ & $\%$ & Volume/ha $\left(\mathrm{m}^{3}\right)$ & $\%$ \\
\hline Wildstand & $\begin{array}{c}5.77 \\
(0.02)\end{array}$ & & $\begin{array}{c}7.2 \\
(0.04)\end{array}$ & & $\begin{array}{c}13.4 \\
(0.17)\end{array}$ & & 21.2 & \\
\hline Mid-Gain & $\begin{array}{c}6.37 \\
(0.03)\end{array}$ & 10.4 & $\begin{array}{c}8.0 \\
(0.04)\end{array}$ & 11.1 & $\begin{array}{c}17.2 \\
(0.20)\end{array}$ & 28.4 & 27.1 & 27.8 \\
\hline Top Cross & $\begin{array}{c}6.70 \\
(0.03)\end{array}$ & 16.1 & $\begin{array}{c}8.3 \\
(0.04)\end{array}$ & 15.3 & $\begin{array}{c}19.9 \\
(0.17)\end{array}$ & 48.5 & 32.4 & 52.8 \\
\hline
\end{tabular}


Table 3. - Variance components and percent of total variation for random effects and F-values and significant levels of fixed effects of Douglas-fir realized gain trial planted on five sites and four spacings and three genetic entries measured at age 12 .

\begin{tabular}{|c|c|c|c|c|c|c|c|c|c|c|}
\hline \multirow[b]{2}{*}{ Source } & \multirow[b]{2}{*}{$d f_{N}$} & \multirow[b]{2}{*}{$d f_{D}$} & \multicolumn{2}{|l|}{ Height } & \multicolumn{3}{|c|}{ Diameter } & \multicolumn{3}{|c|}{ Volume/Tree } \\
\hline & & & F-value & $\operatorname{Pr}>\mathrm{F}$ & & F-value & $\operatorname{Pr}>\mathrm{F}$ & & F-value & $\mathrm{Pr}>\mathrm{F}$ \\
\hline Spacing (Sp) & 3 & 12 & 1.7 & 0.21 & & 7.2 & 0.005 & & 5.2 & 0.016 \\
\hline Genetic entry (G) & 2 & 8 & 33.5 & 0.0001 & & 27.3 & 0.0003 & & 11 & 0.005 \\
\hline Sp*G & 6 & 24 & 0.9 & 0.5 & & 0.5 & 0.8 & & 0.6 & 0.7 \\
\hline & & VC & $\%$ variation & & VC & $\%$ variation & & $V C$ & $\%$ variation & \\
\hline Site (S) & 4 & 12707 & 76.5 & & 277 & 73.9 & & 74 & 65.5 & \\
\hline Block/S (B/S) & 5 & 465 & 2.8 & & 12 & 3.2 & & 4 & 3.5 & \\
\hline$S * S p$ & 12 & 711 & 4.3 & & 22 & 5.9 & & 4 & 3.5 & \\
\hline$B / S^{*} S p$ & 15 & 327 & 2.0 & & 20 & 5.3 & & 12 & 10.6 & \\
\hline$S^{*} \mathrm{G}$ & 8 & 0 & 0.0 & & 0 & 0.0 & & 3 & 2.7 & \\
\hline$B / S^{*} G$ & 10 & 80 & 0.5 & & 1,6 & 0.4 & & 0 & 0.0 & \\
\hline$S * S p * G$ & 24 & 0 & 0.0 & & 0 & 0.0 & & 1 & 0.9 & \\
\hline Residual & 30 & 2316 & 13.9 & & 42 & 11.2 & & 15 & 13.3 & \\
\hline Total & & & 100 & & & 100 & & & 100 & \\
\hline
\end{tabular}

Note: $\mathrm{df}_{\mathrm{N}}$ and $\mathrm{df}_{\mathrm{D}}$ are degrees of freedom of F-ratio numerator and denominator, respectively.

"Sp" is the main plot factor while "G" is the split-plot factor.

Table 4. - Percentage height and diameter gains above controls for mid-gain and top-cross trees in single-tree plots and blocks at $2.9 \times 2.9 \mathrm{~m}$ spacing measured on five test sites of a coastal Douglas-fir realized gain trial at age 12 .

\begin{tabular}{|c|c|c|c|c|c|c|c|c|}
\hline \multirow[b]{3}{*}{ Site } & \multicolumn{4}{|c|}{ Diameter at age 12} & \multicolumn{4}{|c|}{ Height at age 12} \\
\hline & \multicolumn{2}{|c|}{ M G } & \multicolumn{2}{|c|}{$\mathrm{TC}$} & \multicolumn{2}{|c|}{ M G } & \multicolumn{2}{|c|}{ T C } \\
\hline & $S T P^{1}$ & Block $^{2}$ & STP & Block & STP & Block & STP & Block \\
\hline Campbell River & 11.6 & 20.1 & 20.7 & 10.3 & 7.7 & 14.0 & 14.3 & 8.4 \\
\hline Lang Bay & 6.2 & 6.5 & 11.6 & 10.6 & 8.2 & 5.4 & 9.9 & 9.4 \\
\hline Norrish & 11.8 & 9.9 & 19.1 & 30.5 & 11.9 & 13.1 & 16.4 & 25.1 \\
\hline Robertson & 9.6 & 13.5 & 12.9 & 7.7 & 9.0 & 11.0 & 8.6 & 6.4 \\
\hline Spirit Lake & 10.4 & 7.7 & 14.2 & 13.3 & 9.9 & 8.6 & 11.0 & 15.8 \\
\hline Average: & 9.9 & 11.5 & 15.7 & 14.5 & 9.3 & 10.4 & 12.0 & 13.0 \\
\hline
\end{tabular}

${ }^{1}$ single-tree plot, $(2.9 \mathrm{~m}$ spacing).

${ }^{2}$ multiple tree $(10 \times 10)$ plot, $(2.9 \mathrm{~m}$ spacing $)$.

At age 12, averaged across sites and spacings, the observed genetic gains for MG and TC trees in average height ranged from $10.4 \%$ and $16.1 \%$, respectively. Similar gains were observed for diameter (Table 2). For indi- vidual tree volume (the original selection trait), average gains ranged from $28.4 \%$ to $48.5 \%$ for $\mathrm{MG}$ and TC trees, respectively. Observed genetic gains in volume/ha were similar with $27.8 \%$ and $52.8 \%$ above controls (Table 2). 


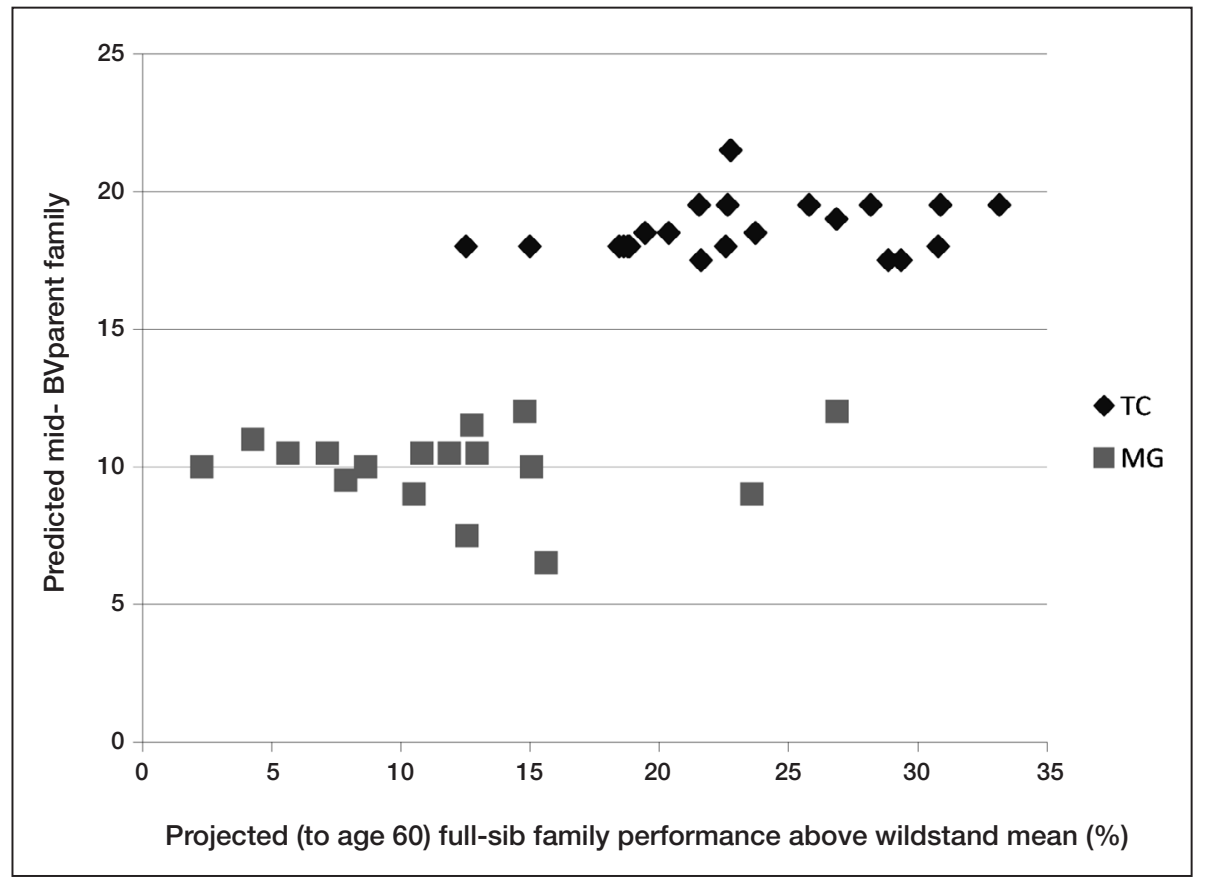

Figure 3. - Scatter diagram of predicted BVs for coastal Douglas-fir families in MG and TC entries and full-sib family performance in total tree volume at four spacings across five test sites.

Mixed model ANOVA revealed highly significant differences for age 12 height, dbh and volume due to genetic entries, but only spacing was significant for diameter and tree volume (Table 3). For all three response variables analyzed, the genetic entry by spacing interaction $(\mathrm{Sp} * \mathrm{G}$ in Table 3) was not significant. Of the random effects in the linear mixed model, site accounted for the largest proportion of the variation for all three variables, and interactions of site by genetic entry and site by spacing by genetic entry accounted for very little of the overall variation (Table 3 ).

To examine the question of there being potential differences in gain estimates between single-tree plots (STP) and the area block plots, we compared the observed gain in height and dbh for the $2.9 \mathrm{~m}$ spacing for MG and TC entries on each test site for both plot types. On average, STP gain estimates were within $2 \%$ of block estimates. While height and dbh gains were similar, dbh gains in TC trees were highest in the STP, suggesting that some of the TC trees may have already established their greater vigour at the expense of the WS and/or MG trees (Table 4).

Correlations between predicted breeding value (for tree volume at age 60) for each full-sib family based on mid-parent BLP and best linear unbiased estimates (BLUEs) of full-sib performance are shown in Figure 3 for both MG and TC families. While the average predicted BV for both groups (i.e., MC, TC) was targeted to be approximately $10 \%$ and $18 \%$ (at age 60 ), respectively, the observed mean family performance in tree volume was $12 \%$ and $23 \%$ above the WS trees. These BLUEs of the full-sib families include the age-age correlation (from age 12 to age 60 ) to facilitate a better comparison with the predicted BLP estimates of mid-parent family BV. It is noteworthy that the variation in actual performance of the tested full-sib families is much larger than the predicted performance based on BLP BV of those families.

The observed top height trajectories and the Bruce (1981) predicted height growth trajectories for each test location and genetic entry are shown in Figure 4. The heights of the MG and TC groups are parallel to and above the curves of the WS seedlings, with the TC seedlings taller than the MG seedlings (except at the Robertson site). Generally, the observed height growth is greater than that predicted by the BRUCE (1981) model at young ages. As the trees age, their height growth pattern more closely parallels the predicted height. At Spirit Lake, however, the test seedlings performed poorest with respect to model expectations as evidenced by the crossing over of the observed and expected height trajectories.

\section{Discussion}

Results from several realized gain studies have been reported for various conifer species, but our study is one of only a few in which the level of predicted gains was assigned a priori to seedlings based on progeny test results (BVs of parents). In other studies, genetically superior seedlings were planted and then their gain was determined as a deviation from control or check lots at the time of data analysis. In this study, we can determine how close predicted gains actually are to family performance in large plots of similar genetic stock. The observed MG and TC individual tree volumes were 

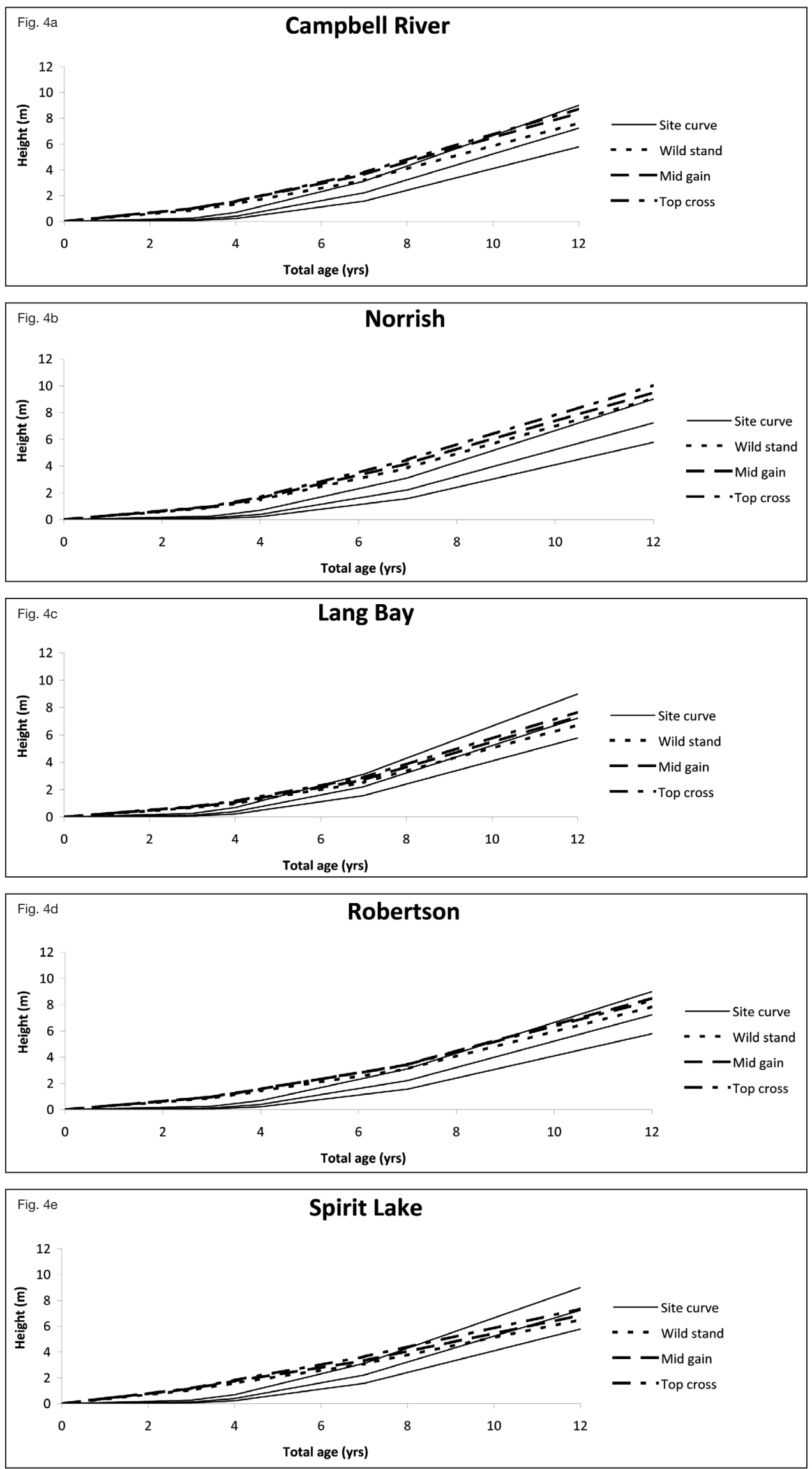

Figure 4. - Observed height trajectories by site and genetic level overlaid on predicted height trajectories from Bruce's (1981) height growth model for site indexes 40, 45, and $50 \mathrm{~m}$ at breast height age 50 .

a) Campbell River; b) Norrish; c) Lang Bay; d) Robertson; e) Spirit Lake. 

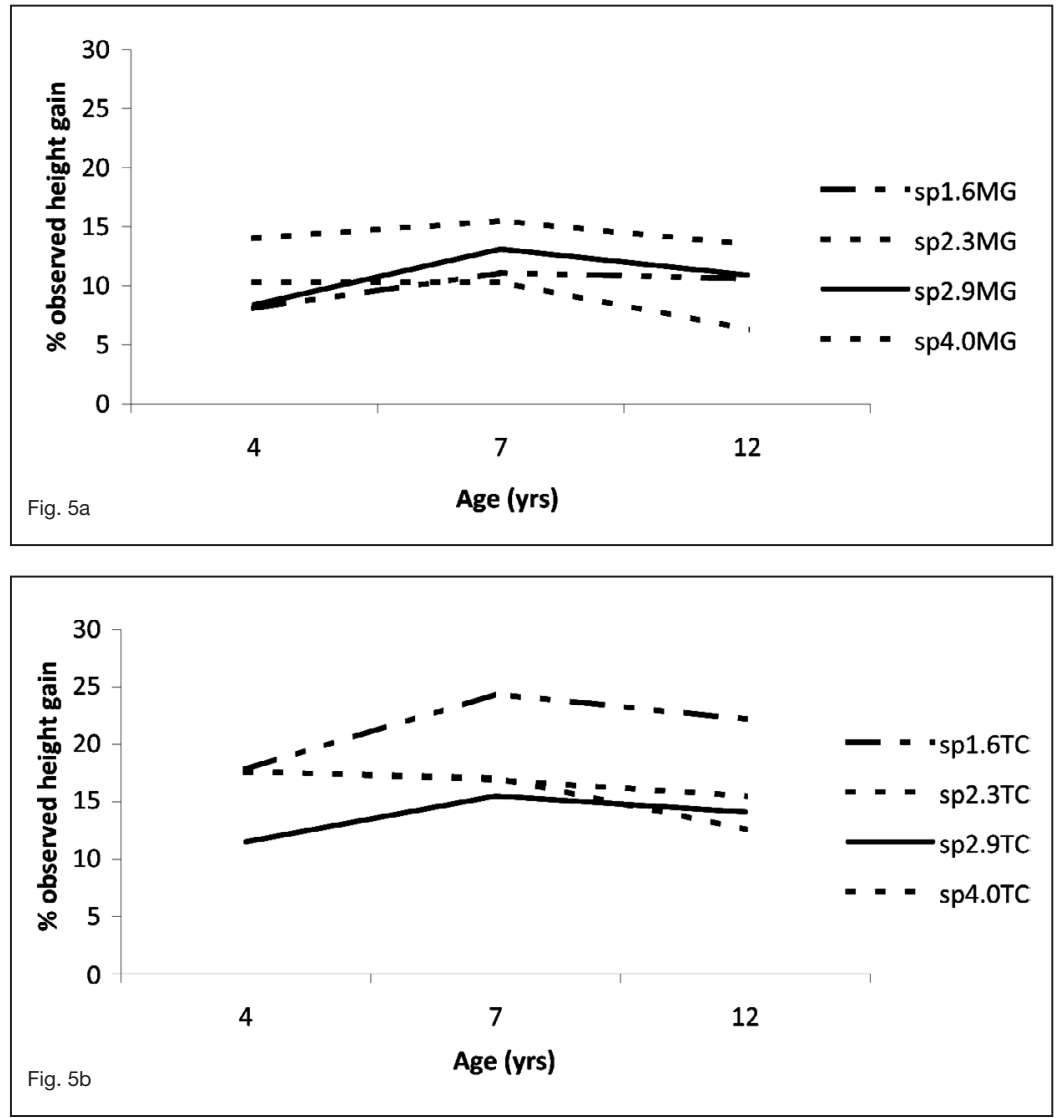

Figure 5. - Observed genetic gains at age 4, 7 and 12 years at four spacings aross five sites for two groups of selected seedlings of coastal Douglas-fir.

a) Mid-gain trees; b) Top-cross trees.

above the predicted values (Table 2 , Figure 3). However, the predicted BVs are adjusted for the uncertainty of selecting parents at age 12 and forecasting their performance to age 60. This age-age correlation (LAMBETH, 1980 ) is 0.5 and if observed performance in our tests at age 12 is compared with predicted, observed gains need to be multiplied by 0.5 as well.

It appears that the estimated percent gains in height are dropping from age 7 to age 12 , as we saw a reduction from $24 \%$ to $22 \%$ for TC trees at $1.6 \mathrm{~m}$ spacing (Figure 5 ); however, this drop is expected due to the fact that the denominator of the gain equation typically increases faster than the numerator as stands mature (CARSON et al., 1999b). For example, the actual growth rate for this treatment combination (TC at $1.6 \mathrm{~m}$ ) for age 7 is $43 \mathrm{~cm} / \mathrm{yr}$, but was larger at $59 \mathrm{~cm} / \mathrm{yr}$ at age 12 .

Spacing by genetic level interactions in our study were not significant in all three response variables. This lack of silvicultural treatment by seedlot interaction was also found by CARSON et al. (1999a) in radiata pine in New Zealand. However, a genetic (familial or parental) by planting density interaction has been recently observed in southern pines, leading to the identification of specific crop and/or competition ideotypes under given planting densities (STAUDHAMMER et al., 2009). While we did not observe a genetic entry by site interaction, individual parents in our study may perform differently under different silvicultural treatments.

STP and area plots, at least up to age 12 , yielded very similar results, but we assume that the congruence so far is likely due to lack of significant crown competition in the STP. As competition with age increases, we expect to see larger differences between STP and our area plots as TC seedlings likely will start to dominate over neighbouring trees of lower genetic quality.

In New Zealand's radiata pine (Pinus radiata D. Don) improvement program, where the primary selected growth trait is diameter, a simple lift in SI did not adequately account for the improvement effects on volume. There, diameter gains were up to five-times greater than height gains (CARSON et al., 1999b), while in our study the levels of gain were very similar between height and dbh. However, as the relationship of height and dbh to calculate volume is not a simple $1: 1$, gains in volume are not linear to gains observed in height and dbh (Table 2); i.e., a simple lift in SI (to account for height gain only) may not adequately project volume gains at rotation in growth and yield models forecasting volume production in second-growth Douglas-fir stands established with genetically improved seed. However, additional years of data will be required to determine whether the accelerated growth of selected families car- 
ries through to rotation (REHFELDT et al., 1991, Hamilton and REHFELDT, 1994) and if indeed a genetic multiplier is required for accurate yield predictions.

For now, we are monitoring if the trees in our five test sites follow the growth trajectories predicted by the BRUCE (1981) height growth model at ages greater than approximately 7 years. With the exception of Spirit Lake, the growth of our seedlings generally parallels the height growth curves for various 'arbitrary' site indices on four of the five test sites (Figure 4). Since the BRUCE (1981) height growth curves were originally fit to data covering a wide range of ages, it is not surprising that the model does not accurately predict height at very young ages across all sites. Furthermore, many of the trees used to develop the height growth model were from natural stands, that were likely subject to brush competition which could explain why the model underpredicts early height growth.

As indicated earlier, growth and yield prediction systems for managed stands of coastal Douglas-fir in British Columbia are height-driven. Therefore, it is critical that the height growth models accurately portray the 'top height' growth of stands, particularly through the early years of establishment and for plantations established with genetically selected stock (almost all seedlings planted in coastal Douglas-fir in B.C are now from selected seed sources). Although the trees in this study are still too young to reliably compare observed versus predicted rotation-age volume gains, height growth mean differences and growth trajectories are similar, and without current major shifts in growth trajectories, height-driven growth and yield systems to predict volume at rotation ages should still be acceptable for stands from genetically selected seed. However, in the future we may have to develop genetic gain multipliers to accurately project volume production at rotation.

\section{Conclusions}

Our results are based on measurements made on trees at age 12 from seed, representing roughly $1 / 5^{\text {th }}$ of final rotation age. Estimates of observed gain based on STP are very similar to the observed gain from the area plots (Table 4), indicating that selections can be made in operational spacings in STP prior to crown closure (onset of competition). However, interpretations based on these data are preliminary, as mid-to-late stand competition is in the early stages. There is evidence that breeding value predictions derived from progeny tests are generally accurate, but sample sizes in progeny tests are, due to cost constraints, restricted and parental breeding values may have a large error associated with them. This error argues for the use of a reasonably large number of selected parents in production populations (seed orchards) to ensure the broad representation of genetic diversity but to also reduce the error associated with estimates of the genetic gains of seedlots used in operational deployment populations.

At this stage, we do not advocate changing methodology for either BV calculation, or how genetic gains are incorporated in growth and yield projection systems (e.g., TIPSY), as the genetically selected seedlings paral- lel the growth trajectories of the WS control seedlings (which present the most accurate SI curves on each particular site). Data from older trees are required to determine whether these relationships hold as stands approach an economic rotation age and whether growth models will require adjustment through genetic gain multipliers.

\section{Acknowledgments}

The following Research Branch, BC Forest Service staff are thankfully acknowledged: NORM POMEROY and Вов НАттIE for technical assistance during test establishment and LISA HAYTON for diligent data management throughout the length of this study; PETER OTT and CHANG-YI XIE for internal reviews of an earlier version of the manuscript. The constructive reviews of two anonymous external reviewers drastically improved the manuscript and are much appreciated.

\section{Literature Cited}

Adams, J. P., T. G. Matney, S. B. Land, K. L. Belli and H.W. DuRZAN JR. (2006): Incorporating genetic parametes into a loblolly pine growht-and-yield model. Can. J. For. Res. 36, 1959-1967.

BRUCE, D. (1981): Consistent height-growth and growthrate estimates for remeasured plots. For. Sci. 27, 711-725.

Buford, M. A. and H. E. Burkhart (1987): Genetic improvement effects on growth and yield of loblolly pine plantations. For. Sci. 33 (3), 707-724.

Carson, S. K., M. O. Kimberly, J. D. Hayes and M. J. CARSON (1999a): The effect of silviculture on genetic gain in growth of Pinus radiata at one-third rotation. Can. J. For. Res. 29, 1979-1984.

Carson, S., O. Garcia and J. Hayes (1999b): Realized gain and prediction of yield with genetically improved Pinus radiata in New Zealand. For. Sci. 45(2), 186-200.

Dhakal, L. P., T. L. White and G. HodGe (1996): Realized genetic gain from slash pine tree improvement. Silvae Genet. 45, 190-197.

Gould, P., R. Johnson, D. Marshall and G. Johnson (2008): Estiamtion of genetic-gain multipliers fior modeling Douglas-fir height and diameter growth. For. Sci. 54(6), 599-596.

Hamilton, D. A. and G. E. Rehfeldt (1994): Using individual tree grwoth projection models to estimate standlevel gains attributable to genetically improved stock. For. Ecol. Mgtmt. 68, 189-207.

LAMBETH, C. C. (1980): Juvenile-mature correlations in Pinaceae and implications for early selection. For. Sci. 26, 571-580.

LAMBETH, C. (2000): Realized genetic gains for first generation improved loblolly pine in 45 tests in coastal North Carolina. South. J. Appl. For. 24(3), 140-144.

MAGNussen, S. (1993): Bias in genetic variance estimates due to spatial autocorrelation. Theor. Appl. Genet. 86, 349-355.

MAGNussen, S. (1989): Effects and adjustments of competition bias in progeny trials with single-tree plots. For. Sci., 532-547.

Mitchell, K. J., M. Stone, S. E. Grout, C. M. Di Lucca, G. D. NIGH and J. W. Goudie et al. (2004): TIPSY. http//www.for.gov.bc.ca/hr. 
Mrode, R. A. (2005): Linear models for the prediction of animal breeding values ( $2^{\text {nd }}$ ed.). Wallingford, Oxfordshire, UK: CABI Publsihing.

Omule, S. A., V. E. Fletcher and K. Polsson (1987): Total and merchantable volume equations for small coastal Douglas-fir. Victoria, BC: Canda-BC FRDA.

ORR-EwING, A. L. (1969): The development of a program for the genetic improvement of Douglas-fir in British Columbia. For. Chron., 395-399.

Rehfeldt, G. E., W. R. WyKoff, R. J. Hoff and R. J. SteinHofF (1991): Genetic gains in growth and simulated yield of Pinus monticola. 37 (1), 326-342.

SAS Institute InC. (2004): SAS OnlineDoc ${ }^{\circledR}$ 9.1.3. Cary, NC. SAS Institute Inc.

St. Clair, J. B., N. L. Mandel and K. J. Jayawickrama (2004): Early realized genetic gains for coastal Douglasfir in the northern Oregon Cascades. West. J. Appl. For. 19(3), 195-201.

Staudhammer, C. L., E. J. Jokela and T. A. Martin (2009): Competition dynamics in pure-versus mixed family stands of loblolly and slash pine in the southeastern United States. Can. J. For. Res. 39, 396-409.

Stoenr, M., A. Yanchuk, X.-Y. XIE and L. SAnchez (2008): Gain and diversity in advanced generation coastal Douglas-fir selections for seed production populations. Tree Gen. Genet. 4, 193-200.
Vergara, R., T. L. White, D. Huber and R. Schmidt (2007): Realized genetic gains of rust resistant selections of slash pine (Pinus elliottii var. elliottii) planted in high rust hazard sites. Silvae Genet. 56(5), 231-242.

Weng, Y. H., K. Tosh, G. Adam, M. S. Fullarton, C. NorFOLK and Y. PARK (2008): Realized genetic gains observed in a first generation seedling seed orchard for jack pine in New Brunswick, Canada. New Forests 36, 285-298.

White, T. L. and G. R. Hodge (1989): Predicting breeding values with applications in forest tree improvement. Kluwer Acad. Publ. Forest Sciences, Vol. 33. Dordrecht, The Netherlands.

WooDs, J. H. (1993): Breeding programs and strategies for Douglas-fir in North America. In: Breeding strategies of important tree species in Canada. Dept. of Natural Res. Canada Info. Rep. M-X-186E. 54p.

XIE, C.-Y. and A. D. YANCHUK (2003): Breeding values of parental trees, genetic worth of seed orchard seedlots, and yields of improved stocks in British Columbia. West. J. Appl. For. 18(2), 88-100.

\title{
Controlled Pollination Methods for Creating Corymbia Hybrids
}

\author{
By G. R. Dickinson ${ }^{1), 2), *)}$, H. M. WALlaCE ${ }^{2)}$ and D. J. LeE ${ }^{2), 3)}$
}

(Received $19^{\text {th }}$ November 2009)

\begin{abstract}
Inter-specific Corymbia hybrids are of increasing interest to plantation forestry, yet there is little knowledge of the most suitable controlled pollination methods for this genus. Inter-specific crosses were made between C. torelliana [CT(maternal parent)] and C. citriodora subsp. variegata $(\mathrm{CCV}), C$. henryi $(\mathrm{CH})$ and $C$. citriodora subsp. citriodora (CCC) using conventional pollination, one-stop pollination (OSP) and artificially-induced protogyny on yellow buds (AIP Y) pollination methods. Additional treatments included AIP on green buds (AIP $\mathrm{G}$ ) and the use of exclusion bags for the OSP and AIP

1) Agri - Science Queensland, Department of Employment, Economic Development and Innovation, P.O. Box 1054, Mareeba, Queensland, 4880, Australia.

$\left.{ }^{2}\right)$ University of the Sunshine Coast, Maroochydore DC, Queensland, 4558, Australia.

$\left.{ }^{3}\right)$ Agri - Science Queensland, Department of Employment, Economic Development and Innovation, LB 16, Gympie, Queensland, 4570, Australia.

*) Author for correspondence: GEOFF Dickinson. Phone +617-40484762, Fax +617 40923593. E-Mail: geoff.dickinson@ deedi.qld.gov.au
\end{abstract}

methods. Inter-specific hybrids $(\mathrm{CT} \times \mathrm{CCV}, \mathrm{CT} \times \mathrm{CH}$ and CT $\times$ CCC) were successfully created using all three pollination methods. The AIP Y treatment provided the highest seed yields and achieved time savings of $>41 \%$ over the conventional and OSP methods, resulting in up to five-fold increases in operator productivity. However, the AIP Y treatment also had the highest C. torelliana contamination levels $(9.3-13.2 \%)$. The use of exclusion bags with the AIP method had minimal effect on contamination rates, indicating a high proportion of selfpollen contamination. Contamination rates varied between maternal parents, suggesting variation in selfcompatibility for $C$. torelliana individuals. AIP using semi-ripe green buds was not effective at reducing selfing and had low operator productivity. The AIP method is suitable for use in a large-scale hybrid breeding program for C. torelliana. When self-pollination effects are managed, it could greatly reduce the costs associated with the production of seed of elite family crosses for commercial forestry deployment.

Key words: Conventional pollination, one-stop pollination, artificially-induced protogyny, self-pollination, spotted gum, Eucalyptus, inter-specific hybrid. 